\title{
MULTIPLICAÇÃO in vitro DE Ficus carica L.: EFEITO DA CINETINA E DO ÁCIDO GIBERÉLICO ${ }^{1}$
}

\author{
In vitro multiplication of Ficus carica L.: kinetin and giberelic acid effects \\ Chrystiane Borges Fráguas ${ }^{2}$, Moacir Pasqual ${ }^{3}$, Alba Regina Pereira ${ }^{4}$
}

\section{RESUMO}

A cultura da figueira é afetada pelo vírus-do-mosaico e a cultura de tecidos é uma alternativa para se proceder à limpeza clonal. Neste trabalho, objetivou-se estudar o efeito da cinetina e $\mathrm{GA}_{3}$ na multiplicação in vitro da figueira. Segmentos nodais foram inoculados em meio de cultura WPM contendo as seguintes combinações de cinetina $\left(0 ; 0,5 ; 1 ; 2\right.$ e 4 mg. $\left.L^{-1}\right)$ e $\mathrm{GA}_{3}\left(0,2,4,6\right.$ e $\left.8 \mathrm{mg} \cdot \mathrm{L}^{-1}\right)$. Avaliaram-se número e comprimento dos brotos, peso da matéria fresca e seca da parte aérea, número de raízes, peso da matéria fresca e seca do sistema radicular e de calos. A utilização de $0,5 \mathrm{mg} . \mathrm{L}^{-1}$ de cinetina promoveu melhor taxa de multiplicação in vitro de Ficus carica. $\mathrm{O} \mathrm{GA}_{3}$ reduziu a formação e multiplicação dos brotos e induziu ao estiolamento, à hiperidricidade, clorose e necrose apical das plântulas.

Termos para indexação: Propagação in vitro, figueira, reguladores de crescimento.

\begin{abstract}
The fig culture is affected by mosaic virus and the tissue culture is an alternative in the clonal cleaning. The kinetin and $\mathrm{GA}_{3}$ effects on in vitro fig multiplication was studied. Nodal segments were inoculated in WPM culture medium containing the following combination of kinetin $\left(0,0.5,1,2\right.$ and $\left.4 \mathrm{mg} . \mathrm{L}^{-1}\right)$ and $\mathrm{GA}_{3}\left(0,2,4,6\right.$ and $\left.8 \mathrm{mg} . \mathrm{L}^{-1}\right)$. The number and length, fresh and dry weigh matter of aerial part, number of roots, fresh and dry weight matter of root system and fresh and dry weight matter of callus were evaluated. The use of kinetin $0.5 \mathrm{mg} . \mathrm{L}^{-1}$ promoted higher rates of in vitro Ficus carica multiplication. The $\mathrm{GA}_{3}$ reduced the formation and shoot multiplication, and induced etiolation, hyperhydricity, clorosis and apical necrosis at the plantlets.
\end{abstract}

Index terms: In vitro propagation, fig, growth regulators.

(Recebido para publicação em 25 de fevereiro de 2003 e aprovado em 15 de abril de 2003)

\section{INTRODUÇÃO}

O Brasil é o maior produtor de figos da América do Sul e ocupa a $11^{\mathrm{a}}$ colocação entre os principais produtores mundiais, sendo o segundo exportador de figo in natura no mundo, superado apenas pela Turquia (FAO, 1998), e a colheita brasileira ocorre na entressafra dos principais países produtores.

No Brasil, é cultivada uma única cultivar, a Roxo de Valinhos, caracterizada pelo seu elevado vigor e produtividade. A maioria dos plantios existentes no Estado de São Paulo apresenta o vírus-do-mosaico, que é transmitido por estaquia, método convencional de propagação da figueira (RIBEIRO, 1999).

Considerando as amplas possibilidades de produção e comercialização do figo nos mercados interno e externo, há necessidade de aperfeiçoamento das técnicas de plantio aliado à obtenção de mudas isentas de patógenos. Um dos objetivos do cultivo in vitro de tecidos vegetais é a obtenção de mudas sadias e limpeza clonal e, por isso, pode ser aplicado na multiplicação da figueira.

Trabalhos in vitro com diversas variedades de Ficus carica têm sido restritos à produção de plantas livres de vírus, mediante cultura meristemas (HAELTERMAN e DOCAMPO, 1994; NOBRE et al., 1998; DEMIRALAY et al., 1998; GUNVER et al., 1998; KUMAR et al., 1998). No Brasil, poucas são as pesquisas realizadas com o cultivo in vitro da figueira 'Roxo de Valinhos', embora os resultados observados por Barbosa et al. (1992), Anjos Sobrinho et al. (1998) e Brum (2001) confirmem a possibilidade da propagação in vitro da figueira.

Embora o meio MS (MURASHIGE e SKOOG, 1962) tenha favorecido o crescimento e desenvolvimento de várias espécies, a utilização de composições mais diluídas, como aquelas do meio WPM (Lloyd e McCown, 1980), para algumas lenhosas, tem fornecido melhores resultados (GRATTAPAGLIA e MACHADO, 1998; BRUM, 2001).

\footnotetext{
1. Parte da dissertação apresentada àUniversidade Federal de Lavras/UFLA - Caixa Postal 37 - 37200-000 - Lavras, MG, pelo primeiro autor. 2. Doutoranda em Horticultura - FCA/UNESP - Caixa Postal 545 - 18618-000 - Botucatu, SP. chrysbf@ig.com.br

3. Professor Titular do Departamento de Agricultura/UFLA.

4. Mestranda em Fitotecnia - Departamento de Agricultura/UFLA.
} 
As citocininas promovem divisão, alongamento e diferenciação celular, retardam a senescência das plantas, promovem a quebra da dominância apical e induzem à proliferação de gemas axilares (TAIZ e ZEIGER, 1991). O tipo e a concentração de citocinina influenciam o processo de multiplicação in vitro. Embora o BAP (6benzilaminopurina) seja a citocinina mais utilizada, não significa que é ideal para todas as espécies. A utilização da cinetina no meio de cultura diminuiu a formação de calos em Ficus carica (JORDAN e ITURRIAGA, 1980). Um procedimento viável para indução múltipla de brotos e regeneração de plântulas foi desenvolvido com gemas apicais coletadas de árvores adultas de Ficus carica 'Gular', utilizando meio MS suplementado com BAP 2 mg. L $^{-1}$ e ANA 0,2 mg. $\mathrm{L}^{-1}$ (KUMAR et al., 1998). Resultado semelhante foi verificado por Brum (2001) com a cultivar Roxo de Valinhos, que observou menor incremento no número total de brotos, com a associação de concentrações superiores a 2 mg. $L^{-1}$ de BAP e baixas concentrações de ANA. Nobre et al. (1998) observaram bons resultados quanto à taxa de multiplicação da figueira 'Berbera' e 'Lampa' (5,3 brotos por explante) utilizando $0,5 \mathrm{mg} . \mathrm{L}^{-1}$ de BAP.

Em alguns trabalhos, constatou-se que melhores resultados para plantas lenhosas foram observados com a substituição do BAP pela cinetina. Aumento na produção de brotos de Salix humboldtiana foi observado utilizando $0,5 \mathrm{mg} . \mathrm{L}^{-1}$ de cinetina (PEREIRA et al., 2000). A utilização de $0,4 \mathrm{mg} . \mathrm{L}^{-1}$ de cinetina estimulou a formação de brotos e o número de folhas por explante de Emblica officinalis (MISHRA et al., 1999).

As giberelinas têm como principais efeitos o alongamento das brotações durante a multiplicação in vitro e varia conforme a interação existente com outros reguladores de crescimento, dependendo da espécie propagada in vitro (GEORGE, 1996). Figueiredo et al. (2001) relatam a necessidade do $\mathrm{GA}_{3}$ para o alongamento das brotações de Rollinia mucosa. Gomes (1999) observou que a utilização de $\mathrm{GA}_{3}$ em concentrações que variam de 1 a $6 \mathrm{mg} . \mathrm{L}^{-1}$ favorece o crescimento e o desenvolvimento in vitro de brotações de moreira, porém, a utilização de 4 e $6 \mathrm{mg} . \mathrm{L}^{-1}$ do regulador promoveu a formação de calos na base do explante.

Com este trabalho, objetivou-se induzir a multiplicação in vitro de brotos de figueira pela da adição de cinetina e $\mathrm{GA}_{3}$ ao meio de cultura WPM.

\section{MATERIAL E MÉTODOS}

Segmentos nodais de plântulas estabelecidas in vitro, com 1 a $2 \mathrm{~cm}$ e duas gemas, foram inoculados em meio de cultura WPM (LLOYD e MCCOWN, 1980) na concentração padrão dos sais, vitaminas e inositol e 20 g. $\mathrm{L}^{-1}$ de sacarose, acrescido de ágar $\left(\right.$ Merk $\left.^{\circledR}\right)$ 0,6\% e pH ajustado para 5,8 antes da autoclavagem.

Os tratamentos consistiram da combinação de cinetina $\left(0,0,5,1,2\right.$ e 4 mg. $\left.\mathrm{L}^{-1}\right)$ e $\mathrm{GA}_{3}(0 ; 2 ; 4 ; 6$ e 8 $\left.\mathrm{mg} . \mathrm{L}^{-1}\right)$. Os frascos, com capacidade para $250 \mathrm{ml}$, contendo os explantes foram mantidos em sala de crescimento, com irradiância de $35 \mu$ mol. $\mathrm{m}^{-2}$.s. ${ }^{-1}$, temperatura de $27 \pm 1^{\circ} \mathrm{C}$ e fotoperíodo de 16 horas.

$\mathrm{O}$ delineamento inteiramente casualizado em esquema fatorial 5 x 5 foi utilizado com cinco repetições e quatro plântulas por parcela. Após 60 dias, foram avaliados número e comprimento dos brotos, peso da matéria fresca e seca da parte aérea, número de raízes e peso da matéria fresca e seca do sistema radicular.

\section{RESULTADOS E DISCUSSÃO}

Observaram-se rizogênese nos tratamentos que não continham cinetina e a formação de calos na presença de cinetina, independente da suplementação com $\mathrm{GA}_{3}$.

Maior número de brotos $(4,25)$ foi observado com 2,45 mg.L $L^{-1}$ de cinetina na ausência de $\mathrm{GA}_{3}$ (Figura 1). Porém, a partir da concentração de $2 \mathrm{mg} . \mathrm{L}^{-1}$ de cinetina, observou-se a formação de brotos pequenos e vitrificados. Com a utilização de $0,5 \mathrm{mg} . \mathrm{L}^{-1}$ de cinetina na ausência de $\mathrm{GA}_{3}$, obtiveram-se 3,36 brotos. Nessa condição, a qualidade dos brotos foi visualmente melhor, ou seja, com comprimento maior, sem hiperidricidade e com raízes. Provavelmente, essa cultivar requer baixa concentração de citocinina para sua multiplicação, uma vez que altas concentrações levaram a desordens morfológicas e fisiológicas, tais como hiperidricidade.

A presença do $\mathrm{GA}_{3}$ diminuiu o número de brotos e as folhas formadas mostravam-se alongadas e cloróticas. Nas concentrações de 6 e $8 \mathrm{mg} . \mathrm{L}^{-1}$ de $\mathrm{GA}_{3}$, na presença de cinetina, observou-se maior número de brotos vitrificados.

Observou-se que o aumento das concentrações de cinetina induziu ao decréscimo no comprimento dos brotos, principalmente na ausência de $\mathrm{GA}_{3}$ (Figura 2). Quando se utilizaram as concentrações de 2, 4, 6 e 8 mg. $\mathrm{L}^{-1}$ de $\mathrm{GA}_{3}$, a redução no comprimento foi menor. $\mathrm{O}$ maior comprimento $(9,14 \mathrm{~cm})$ foi observado com 6 mg. $L^{-1}$ de $\mathrm{GA}_{3}$, na ausência de cinetina. Esse maior comprimento obtido na presença de $\mathrm{GA}_{3}$ se deve ao excessivo estiolamento das brotações, o que não é desejado, além das brotações apresentarem hiperidricidade, folhas cloróticas, alongadas e necrose apical. 


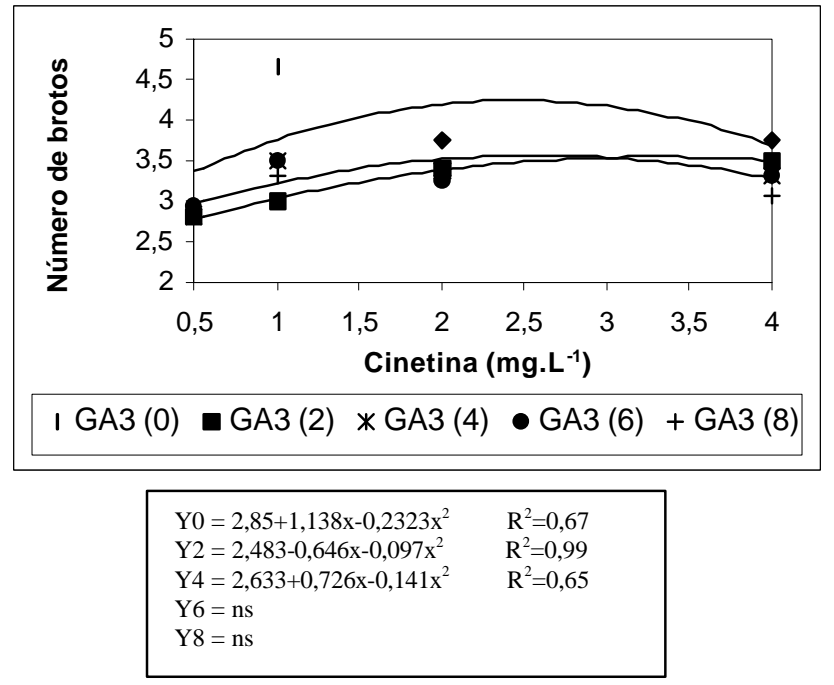

FIGURA 1 - Número de brotos de plântulas cultivadas em meio de cultura WPM em diferentes concentrações de cinetina e $\mathrm{GA}_{3}$. UFLA, Lavras-MG, 2002.

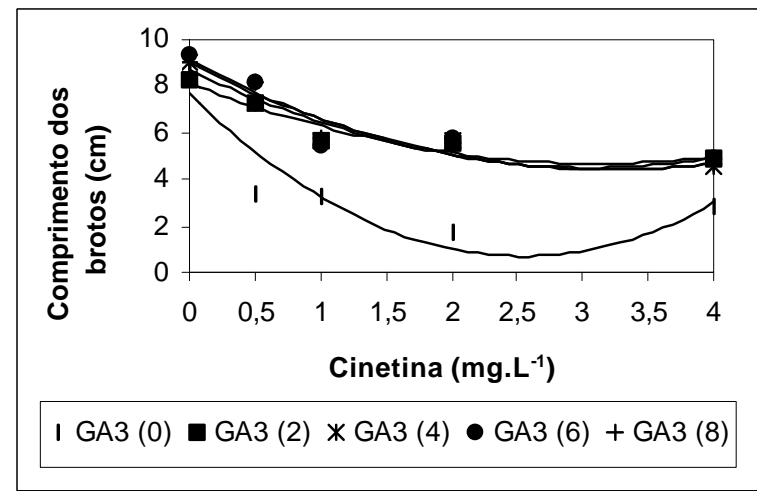

\begin{tabular}{|ll|}
$\mathrm{Y} 0=7,684-5,497 x+1,081 \mathrm{x}^{2}$ & $\mathrm{R}^{2}=0,83$ \\
$\mathrm{Y} 2=8,132-2,206 \mathrm{x}+0,353 \mathrm{x}^{2}$ & $\mathrm{R}^{2}=0,92$ \\
$\mathrm{Y} 4=8,660-2,605 \mathrm{x}+0,402 \mathrm{x}^{2}$ & $\mathrm{R}^{2}=0,90$ \\
$\mathrm{Y} 6=9,142-3,045 \mathrm{x}+0,499 \mathrm{x}^{2}$ & $\mathrm{R}^{2}=0,86$ \\
$\mathrm{Y} 8=9,002-2,853 \mathrm{x}+0,444 \mathrm{x}^{2}$ & $\mathrm{R}^{2}=0,92$ \\
\hline
\end{tabular}

FIGURA 2 - Comprimento dos brotos de plântulas cultivadas em meio de cultura WPM em diferentes concentrações de cinetina e $\mathrm{GA}_{3}$. UFLA, Lavras-MG, 2002.

Resultados semelhantes foram observados por Biasi et al. (1994), que verificaram, na propagação in vitro do abacateiro, que a adição de $\mathrm{GA}_{3}$ ao meio de cultura aumenta a porcentagem de brotações anormais, com folhas alongadas, retorcidas, cloróticas, quebradiças e de fácil abscisão. Deccetti (2000) relatou o efeito prejudicial do $\mathrm{GA}_{3}$ no desenvolvimento de brotações de Annona glabra, além da ocorrência de necrose apical e abscisão foliar.
Quando se utilizou $0,5 \mathrm{mg} . \mathrm{L}^{-1}$ de cinetina na ausência de $\mathrm{GA}_{3}$, obtiveram-se $5,2 \mathrm{~cm}$ de comprimento e não foi observada má formação dos brotos. A obtenção de brotações bem formadas e de maior tamanho proporciona rápido crescimento das plântulas e diminuição no tempo de permanência no laboratório, otimizando a produção de mudas e reduzindo o custo.

Observou-se que o maior peso foi obtido na ausência de $\mathrm{GA}_{3}$ e cinetina (Figuras $3 \mathrm{~A}$ e B), mas nessa 
condição houve apenas o crescimento e desenvolvimento do segmento nodal inicialmente inoculado, não havendo multiplicação. Quando se utilizou 0,5 $\mathrm{mg} . \mathrm{L}^{-1}$ de cinetina, na ausência do $\mathrm{GA}_{3}$, verificaramse $0,437 \mathrm{~g}$ para peso da matéria fresca e $0,032 \mathrm{~g}$ para peso da matéria seca da parte aérea dos brotos multiplicados.

Embora a formação radicular tenha sido observada na ausência de cinetina, na concentração de 0,5 mg. $L^{-1}$ e na ausência de $\mathrm{GA}_{3}$ também se verificou média de 2,2 raízes. Verificou-se que o aumento das concentrações de $\mathrm{GA}_{3}$ induziu ao decréscimo no número de raízes formadas e no peso da matéria fresca e seca do sistema radicular (Figuras 4A, B e C). Maior número de raízes $(3,39)$ e peso da matéria fresca $(0,174 \mathrm{~g})$ e seca $(0,0218 \mathrm{~g})$ do sistema radicular foram observados na ausência de $\mathrm{GA}_{3}$. Possivelmente, as concentrações utilizadas foram elevadas para Ficus carica, o que prejudicou seu enraizamento, sendo o conteúdo endógeno do explante suficiente para promover o enraizamento.
Kochba et al. (1974) citam que a presença de ácido giberélico no meio de cultura proporciona a iniciação de uma zona meristemática radicular e/ou estimula o desenvolvimento de uma zona radicular existente. Todavia, quando aplicado em concentrações elevadas, impede a formação de raízes. De modo semelhante, Deccetti (2000) observou alto percentual de enraizamento e maior número de raízes em Annona glabra na ausência de regulador de crescimento.

O peso da matéria fresca e seca de calo aumentou linearmente com o aumento das concentrações de cinetina (Figura 5A e B). Observou-se maior peso da matéria fresca $(1,331 \mathrm{~g})$ e seca $(0,08 \mathrm{~g})$ de calos, com $4 \mathrm{mg} . \mathrm{L}^{-1}$ de cinetina. Possivelmente houve um desbalanço hormonal que se intensificou com o aumento das concentrações de cinetina. Quando se adicionou $0,5 \mathrm{mg} . \mathrm{L}^{-1}$ de cinetina ao meio de cultura, menor peso da matéria fresca $(0,555 \mathrm{~g})$ e seca $(0,028 \mathrm{~g})$ de calos foi observado.

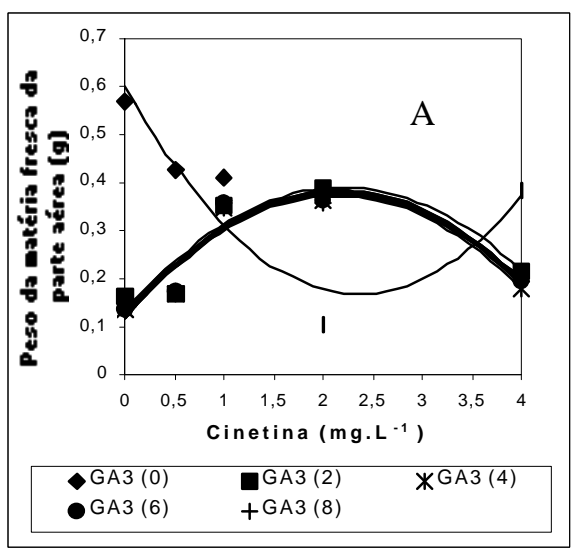

$$
\begin{array}{ll}
\mathrm{Y} 0=0,601-0,367 \mathrm{x}+0,077 \mathrm{x}^{2} & \mathrm{R}^{2}=0,86 \\
\mathrm{Y} 2=0,134+0,234 \mathrm{x}-0,053 \mathrm{x}^{2} & \mathrm{R}^{2}=0,84 \\
\mathrm{Y} 4=0,120+0,239 \mathrm{x}-0,056 \mathrm{x}^{2} & \mathrm{R}^{2}=0,88 \\
\mathrm{Y} 6=0,122+0,241-0,055 \mathrm{x}^{2} & \mathrm{R}^{2}=0,86 \\
\mathrm{Y} 8=0,123+0,229-0,053 \mathrm{x}^{2} & \mathrm{R}^{2}=0,85
\end{array}
$$

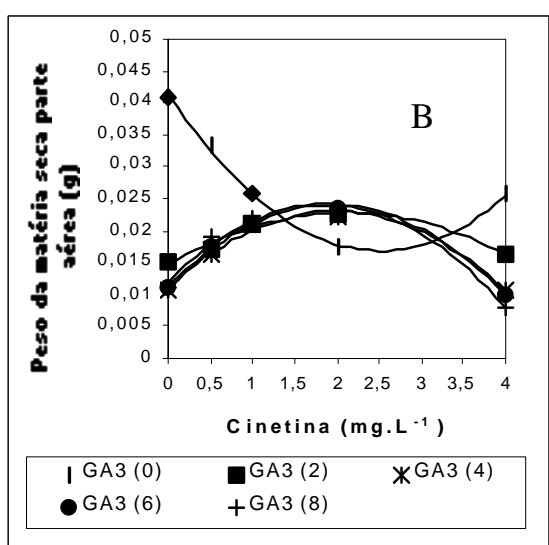

$\mathrm{Y} 0=0,041-0,019 \mathrm{x}+0,003 \mathrm{x}^{2} \quad \mathrm{R}^{2}=0,99$ $\mathrm{Y} 2=0,014+0,008 \mathrm{x}-0,002 \mathrm{x}^{2} \quad \mathrm{R}^{2}=0,96$ $\begin{array}{ll}Y 2=0,014+0,008 x-0,002 x^{2} & R^{2}=0,96 \\ Y 4=0,011+0,012 x-0,003 x^{2} & R^{2}=0,99\end{array}$ $\mathrm{Y} 6=0,011+0,013 \mathrm{x}-0,003 \mathrm{x}^{2} \quad \mathrm{R}^{2}=0,99$ $\mathrm{Y} 8=0,012+0,013 \mathrm{x}-0,003 \mathrm{x}^{2} \quad \mathrm{R}^{2}=0,98$

FIGURA 3 - Peso da matéria fresca (A) e seca (B) da parte aérea dos brotos de plântulas cultivadas em meio de cultura WPM em diferentes concentrações de cinetina e GA . UFLA, Lavras-MG, 2002. 


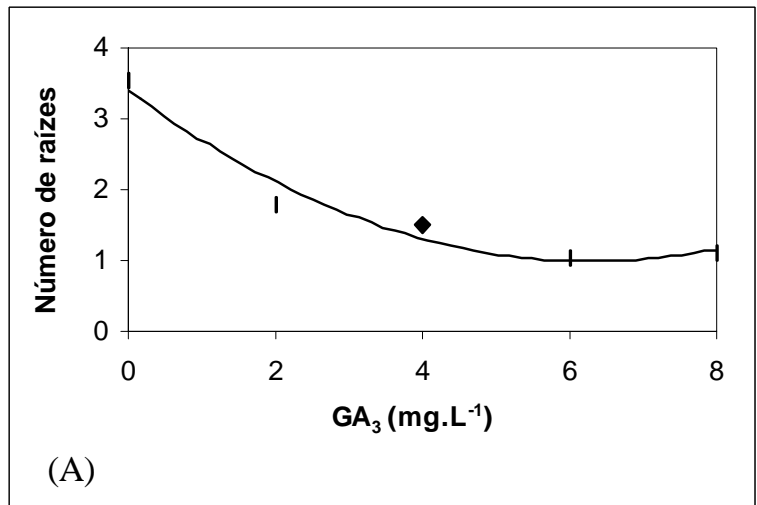

(A)

$Y=3,396-0,763 x+0,0605 x^{2} \quad R^{2}=0,96$

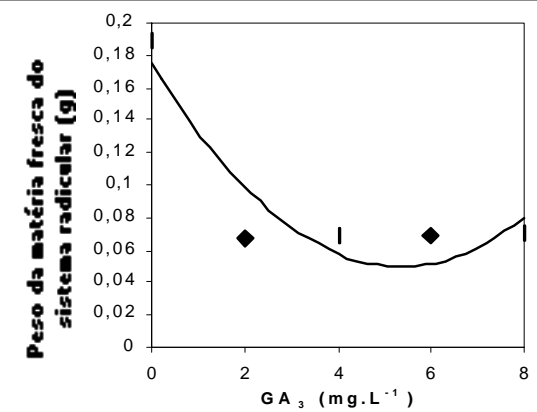

(B)

$Y=0,174-0,046 x+0,0043 x^{2} \quad R^{2}=0,85$

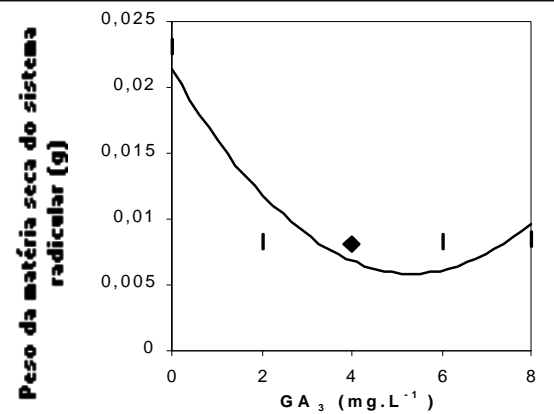

(C)

$Y=0,0218-0,006 x+0,00056 x^{2} \quad R^{2}=0,86$

FIGURA 4 - Número de raízes (A) e peso da matéria fresca (B) e seca (C) do sistema radicular dos brotos cultivados em meio de cultura WPM em diferentes concentrações de cinetina e GA. UFLA, Lavras-MG, 2002.

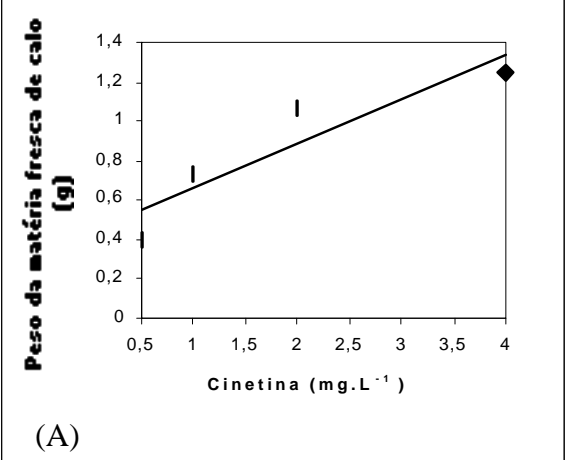

$\mathrm{Y}=0,445+0,2215 \mathrm{x} \quad \mathrm{R}^{2}=0,83$

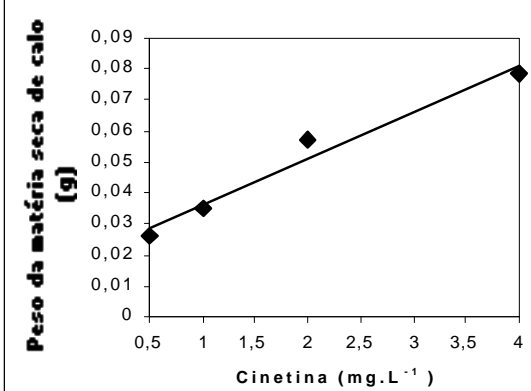

(B)

$$
\mathrm{Y}=0,0214+0,0148 \mathrm{x} \quad \mathrm{R}^{2}=0,97
$$

FIGURA 5 - Peso da matéria fresca (A) e seca (B) de calos dos brotos cultivados em meio de cultura WPM em diferentes concentrações de cinetina e GA . UFLA, Lavras-MG, 2002. 


\section{CONCLUSÕES}

A utilização de $0,5 \mathrm{mg} . \mathrm{L}^{-1}$ de cinetina promove multiplicação de Ficus carica a partir de segmentos nodais. $\mathrm{O} \mathrm{GA}_{3}$ reduz a formação e multiplicação dos brotos e induz ao estiolamento, hiperidricidade, clorose e necrose apical das plântulas.

\section{REFERÊNCIAS BIBLIOGRÁFICAS}

ANJOS SOBRINHO, A. dos; PASQUAL, M.; PAIVA, P. D. de O. Efeito de diferentes concentrações de BAP sobre o desenvolvimento "in vitro" de gemas apicais de figo. In: CONGRESSO BRASILEIRO DE FRUTICULTURA, 15., 1998, Poços de Caldas. Resumos... Poços de Caldas: Sociedade Brasileira de Fruticultura, 1998. p. 347.

BARBOSA, W.; CAMPO-DALL'ORTO, F. A.; OJIMA, M.; MARTINS, F. P.; BOVI, V.; CASTRO, J. L. de. Produção de mudas da figueira 'Roxo de Valinhos' através da cultura in vitro. O agronômico, Campinas, v. 44, n. 1/3, p. 6-18, jan./dez. 1992.

BIASI, L. A.; KOLLER, O. C.; KÄMPF, A. N. Micropropagação do abacateiro 'Ouro Verde' a partir de segmentos nodais. Pesquisa Agropecuária Brasileira, Brasília, v. 29, n. 7, p. 1051-1058, 1994.

BRUM, G. R. Micropropagação da figueira (Ficus carica L.) 'Roxo de Valinhos'. 2001. 41 p. Dissertação (Mestrado em Fitotecnia) - Universidade federal de Lavras, Lavras, 2001.

DECCETTI, S. F. C. Propagação in vitro de Annona glabra L. 2000. 101 p. Dissertação (Mestrado em Fisiologia Vegetal) - Universidade Federal de Lavras, Lavras, 2000 .

DEMIRALAY, A.; YALCIN-MENDI, Y.; AKAKACAR, Y.; CETINER, S.; AKSOY, U.; FERGUSON, L.; HEPAKSOY, S. In vitro propagation of Ficus carica L. var. Bursa Siyahi through meristem culture. Acta Horticulturae, Wageningenn, v. 480, p. 165-167, 1998.

FOOD AGRICULTURAL ORGANIZATION. Disponível em: <http//www. fao. org>. Acesso em: 25 abr. 1998.

FIGUEIREDO, S. F. L.; ALBARELLO, N.; VIANA, V. R. C. Micropropagation of Rollinia mucosa (Jacq.) Baill. In Vitro Cellular \& Developmental Biology Plant, Wallingford, v. 37, n. 4, p. 471-475, 2001.
GEORGE, E. F. Plant propagation by tissue culture: part 1: the technology. 2. ed. Edington: Exegetics, 1996. $1574 \mathrm{p}$.

GOMES, G. A. C. Propagação in vitro de Moreira (Maclura tinctoria). 1999. 91 p. Dissertação (Mestrado em Fisiologia Vegetal) - Universidade Federal de Lavras, Lavras, 1999.

GRATTAPAGLIA, D.; MACHADO, M. A. Micropropagação. In: TORRES, A.; CALDAS, L. S.; BUSO, J. A. (Eds.). Cultura de tecidos e transformação genética de plantas. Brasília, DF: EMBRAPA, 1998. v. 1, p. 183-260.

GUNVER, G.; ERTAN, E.; AKSOY, U.; FERGUSON, L.; HEPAKSOY, S. A study on the propagation of figs by the tissue culture techniques. Acta Horticulturae, Amsterdam, n. 480, p. 169-172, 1998.

HAELTERMAN, R. M.; DOCAMPO, D. M. In vitro propagation of mosaic-free fig (Ficus carica L.) cultivars, using thermotherapy and shoot tip cultures. Revista de Investigaciones Agropecuarias, Buenos Aires, v. 25, n. 3, p. 15-22, 1994.

JORDAN, M.; ITURRIAGA, L. Formación de raices en entrenudos de higuera (Ficus carica L. cv. Adriatic) cultivados in vitro. Ciencia Investiones Agricolas, Buenos Aires, v. 7, n. 2, p. 149-151, 1980.

KOCHBA, J.; BUTTON, J.; SPIEGEL-ROY, P.; BORNMAN, C. H.; KOCHABA, M. Stimulation of rooting of citrus embryoids by gibberelic acids and adenini sulphate. Annals of Botany, London, v. 38, p. 795-802, 1974.

KUMAR, V.; RADHA, A.; CHITA, S. K. In vitro plant regeneration of fig (Ficus carica L. cv. Gular) using apical buds from mature trees. Plant Cell Reports, New York, v. 17, n. 9, p. 717-720, June 1998.

LLOYD, G.; McCOWN, B. Use of microculture for production and improvement of Rhododendron spp. HortScience, Alexandria, v. 15, p. 416, 1980.

MISHRA, M.; SAXENA, R. P.; PATHAK, R. K.; SRIVASTAVA, A. K. Studies on micropropagation of aonla (Emblica officinalis Gaertn). Progressive Horticulture, Chaubattia, v. 31, n. 3/4, p. 116-122, 1999. 
MURASHIGE, T.; SKOOG, F. A revised medium for rapid growth and bioassays with tobacco tissue cultures. Physiologia Plantarum, Copenhagen, v. 15, n. 3, p. 473-497, 1962.

NOBRE, J.; ROMANO, A.; AKSOY, U.; FERGUSON, L.; HEPAKSOY, S. In vitro cloning of Ficus carica L. adult trees. Acta Horticulturae, Amsterdam, n. 480, p. 161-164, 1998.

PEREIRA, A. M. S.; BERTONI, B. W.; MORAES, R. M.; FRANCA, S. C. Micropropagation of Salix humboldtiana Hild. Revista Brasileira de Plantas Medicinais, v. 2, n. 2, p. 17-21, 2000.

RIBEIRO, I. J. A. Doenças da figueira. In: CORRÊA, L. S. de; BOLIANI, A. C. (Eds.).

Cultura da figueira: do plantio à comercialização. Ilha Solteira: FAPESP, 1999. p. 151164.

TAIZ, L.; ZEIGER, E. Cytokinins. In: Plant

Physiology. California: Cummings, 1991. cap. 17, p. 452-471. 